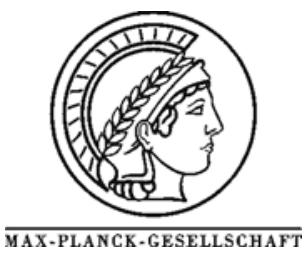

\title{
n-Butane Isomerization Catalyzed by Sulfated Zirconia Nanocrystals Supported on Silica or $\gamma$-Alumina
}

\author{
X. Yang, R.E. Jentoft, F.C. Jentoft*
}

Department of Inorganic Chemistry, Fritz-Haber-Institute of the MPG, Faradayweg 4-6, 14195 Berlin, Germany

*Corresponding author: e-mail jentoft@ffhi-berlin.mpg.de,

Reveived 1 November 2005; accepted 4 November 2005

\begin{abstract}
Supported sulfated zirconia catalysts with zirconia contents of 10,20 and $50 \mathrm{wt} \%$ were prepared by impregnation of $\mathrm{SiO}_{2}$ and $\gamma-\mathrm{Al}_{2} \mathrm{O}_{3}$ supports with $\mathrm{H}_{2} \mathrm{SO}_{4} / \mathrm{Zr}\left(\mathrm{SO}_{4}\right)_{2}$ solutions followed by calcination at $923 \mathrm{~K}$. The catalysts were characterized by X-ray diffraction, extended X-ray absorption fine structure measurements, thermal analysis, UV-vis spectroscopy, and electron microscopy. Tetragonal zirconia was detected in all silicasupported samples but only in the $50 \mathrm{wt} \%$ zirconia-containing alumina-supported sample, indicating high dispersion of zirconia on alumina. Alumina-supported samples retained additional sulfate, at least in part as $\mathrm{Al}_{2}\left(\mathrm{SO}_{4}\right)_{3}$. All samples were active in $n$-butane isomerization (1kPa $n$ butane, $378 \mathrm{~K}$ ). There was no relation between the presence of tetragonal zirconia in these samples and the catalytic performance.
\end{abstract}

Keywords: sulfated zirconia, supported catalyst, $n$-butane isomerization, bulk crystalline phase, alumina, silica, XRD, TEM, SEM, EXAFS, thermal analysis

\section{Introduction}

Sulfated zirconia (SZ) is an interesting catalyst for the skeletal isomerization of short chain alkanes because it is already active at room temperature, where the valuable branched alkanes are thermodynamically favored in comparison to the straight chain isomers [1]. Typical of the SZ catalysts is the reaction profile with time on stream, which features an induction period, a rather short-lived maximum activity and a decline to a much lower steady state activity [2]. The deactivation can be prevented e.g. through addition of platinum together with the presence of hydrogen in the feed $[3,4]$. Nevertheless, it remains unclear why deactivation of pure sulfated zirconia is not complete, and the question arises whether there might be different types of sites responsible for initial and long term catalytic behavior. It has been suspected that two types of sites exist [5], but despite more than two decades of intense investigation there is no defined picture of the nature and structure of the sites that give the SZ catalysts high activity at low temperature $[6,7]$.

One of the important characteristics of the active SZ catalyst is the crystalline zirconia bulk. Although there have been recent reports of active SZ catalysts with monoclinic or cubic zirconia phases $[8,9]$, the majority of the literature suggests that a tetragonal zirconia phase is a necessary part of an active SZ catalyst [2-10,11]. The activity of SZ can be improved by 1 to 2 orders of magnitude through the addition of small amounts of a second metal component as promoter, e.g., $\mathrm{Mn}$ or $\mathrm{Fe}$ [12-14]. It has been found that one of the effects of these promoters is the stabilization of the tetragonal (cubic) phase by incorporation of the $\mathrm{Mn}$ or Fe cations into the zirconia lattice $[15,16]$. Furthermore, mechanical stress in the form grinding, milling, or pressing-typical laboratory practices for homogenization or wafer fabrication - can convert tetragonal into monoclinic zirconia, and the phase change is accompanied by a decrease of catalytic activity for $n$-butane isomerization [17]. These observations as well as the effect of the promoters support the idea of some role of the zirconia bulk phase in generation of the active sites.

The aim of the present work is to further test the hypothesis of two types of sites and to link the presence of either type to a particular crystalline phase. Our strategy is to prepare SZ catalysts that are neither monoclinic, tetragonal, nor cubic, and to compare the catalytic behavior of these 
catalysts with that of "traditional" catalysts with a tetragonal zirconia bulk. Two routes leading to SZ catalysts without a bulk crystalline phase have been taken. One was to prepare sulfated zirconia that consists only of amorphous zirconia walls similar to MCM-41. With a mean pore diameter of ca. $2 \mathrm{~nm}$ and a pore wall thickness at ca. $1 \mathrm{~nm}$, a majority of the $\mathrm{Zr}$ atoms are exposed at internal surfaces, and a bulk zirconia crystalline phase is absent. The material is active for $n$ butane isomerization but less so than the traditional (tetragonal) SZ catalyst. These results have been reported in a separate paper [18]. The second route was to support SZ on high surface area materials such as alumina and silica. If a high level of dispersion is achieved, SZ will be present in the form of fine particles or thin layers without a crystalline bulk. The results with respect to the second route are presented and discussed below.

The literature reports on zirconia-alumina $[19,20]$ and zirconia-silica [21-25] mixed oxides in various compositions, and zirconia has been dispersed on alumina [26-29] and on silica [26,27,30-33]. Zirconium has been embedded in the walls of MCM-41 [34-37] and SBA-15 [38]. Sulfated mixed oxides of zirconia and alumina, alumina-supported SZ, and physical mixtures of SZ and $\gamma$-alumina were tested for $n$-butane [38-42] and $n$-hexane isomerization [43-45]; Ptcontaining physical mixtures of SZ and $\gamma$-alumina or silica have been tested as catalysts for the hydroisomerizationcracking of $n$-octane [46]. Sulfated zirconia-silica mixed oxides [47] and silica- (also MCM-41) supported SZ were found active for the isomerization of $n$-butane [40,42,48,49], $n$-pentane [50], or $n$-hexane [51] and for a number of other reactions [50-59]. SZ and aluminum-promoted SZ have been supported on MCM-41 and SBA-15 [60-62]. Silicon has not been used as a minority species in SZ, i.e. as a promoter, while aluminum-promoted SZ [63] was tested in $n$-butane [64-69], isobutane [70,71], and $n$-pentane isomerization [64], and benzoylation of toluene with benzoyl chloride $[64,72]$.

Most of the above cited papers were aimed at generating new, more active catalysts, and characterization emphasizes acidity. The goal of our work was to relate the catalytic performance, resolved in short-term and long term behavior, to zirconia dispersion and bulk structure. For this purpose, $\mathrm{Zr}\left(\mathrm{SO}_{4}\right)_{2}$ was impregnated via the incipient wetness method in varying amounts onto either amorphous silica or $\gamma$ alumina. The two series of catalysts were characterized and their reaction profiles in $n$-butane isomerization were investigated.

\section{Experimental}

\section{Catalyst preparation}

The support materials, amorphous silica (Merck Kieselgel $500, \mathrm{~A}_{\mathrm{BET}} \approx 500 \mathrm{~m}^{2} / \mathrm{g}$ ) and $\gamma$-alumina crystallites (ALON, $\mathrm{A}_{\mathrm{BET}} \approx 200 \mathrm{~m}^{2} / \mathrm{g}$ ) were calcined at $773 \mathrm{~K}$ for $4 \mathrm{~h}$ before the active component was added. The loading of SZ was done by incipient wetness impregnation using aqueous solutions of $\mathrm{Zr}\left(\mathrm{SO}_{4}\right)_{2}$. For the impregnation, calculated amounts of $\mathrm{Zr}\left(\mathrm{SO}_{4}\right)_{2} \bullet 4 \mathrm{H}_{2} \mathrm{O}$ (Alfa Aesar, 99\%) were dissolved in $10-20 \mathrm{ml}$ of water and $0.04-0.4 \mathrm{ml}$ of $98 \% \mathrm{H}_{2} \mathrm{SO}_{4}$. The solutions were added drop-wise to $2-4 \mathrm{~g}$ of each support within a time of $3 \mathrm{~h}$, achieving samples of 10, 20, and $50 \mathrm{wt} \% \mathrm{ZrO}_{2}$. Samples were calcined for $3 \mathrm{~h}$ at $923 \mathrm{~K}$. Unsupported $\mathrm{Zr}\left(\mathrm{SO}_{4}\right)_{2} \bullet 4 \mathrm{H}_{2} \mathrm{O}$ and a commercial SZ catalyst, MEL Cat. XZO 682/01 (MEL Chemicals) were calcined at $923 \mathrm{~K}$ for use as reference catalysts.

\section{Characterization}

$\mathrm{X}$-ray diffractograms (XRD) were recorded in transmission geometry using a STOE STADI-P X-ray diffractometer equipped with a primary monochromator and a curved position sensitive detector with an internal resolution of $0.01^{\circ}$, and employing $\mathrm{Cu} \mathrm{K \alpha}$ radiation $(\lambda=1.542 \AA)$. The range of $2 \theta=20^{\circ}$ to $70^{\circ}$ was scanned in steps of $0.03^{\circ}(18 \mathrm{~s}$ per point). Phase identification was performed using the JCPDS powder diffraction files (PDF-2 set).

Thermogravimetric and differential thermal analysis (TG/DTA) were carried out on a SEIKO microbalance with a heating rate of $10 \mathrm{~K} / \mathrm{min}$ from room temperature to 1173 $\mathrm{K}$. The sample was exposed to a synthetic air flow of 100 $\mathrm{ml} / \mathrm{min}$. Thermogravimetry and differential scanning calorimetry (TG/DSC) were measured on a NETZSCH STA 449 $\mathrm{C}$ with a heating rate of $10 \mathrm{~K} / \mathrm{min}$ from room temperature to $1373 \mathrm{~K}$ and with a synthetic air flow of $100 \mathrm{ml} / \mathrm{min}$.

Scanning electron microscopy and energy dispersive X-ray analysis (SEM/EDX) were conducted on a Hitachi S4000 microscope equipped with a cold field emission gun and an energy dispersive X-ray detector at an acceleration voltage of $10 \mathrm{kV}$. Transmission electron microscopy was performed on a Philips TEM/STEM CM 200 FEG operated at $200 \mathrm{kV}$.

Diffuse reflectance UV-vis spectra were acquired with a PerkinElmer Lambda 9 spectrometer in the range of $250-800 \mathrm{~nm}$ with a scan speed of $240 \mathrm{~nm} / \mathrm{min}$ against Spectralon $^{\circledR}$ (Labsphere) as a white standard.

X-ray absorption spectra of the Zr K edge (17.998 $\mathrm{keV}$ ) were recorded at beamline X1 at the Hamburger Synchrotron Radiation Laboratory, HASYLAB, using a Si(311) double crystal monochromator. The storage ring operated at $4.45 \mathrm{GeV}$ with injection currents of $150 \mathrm{~mA}$. X-ray absorption fine structure (XAFS) analysis was performed using the software package WinXAS v2 [73]. Details about the XAFS analysis procedure employed can be found in reference [74].

\section{Catalytic tests}

Catalytic tests were carried out in a flow-through fixed bed reactor with an internal diameter of $13 \mathrm{~mm}$. Catalysts containing $200 \mathrm{mg} \mathrm{ZrO}_{2}$ were charged and activated at $723 \mathrm{~K}$ for $90 \mathrm{~min}$ in a nitrogen flow of $30 \mathrm{ml} / \mathrm{min}$. After cooling to $378 \mathrm{~K}$, a flow of $1 \mathrm{vol} \% n$-butane in $\mathrm{N}_{2}$ at a rate of $30 \mathrm{ml} / \mathrm{min}$ was fed through the reactor at atmospheric 
pressure. The weight hourly space velocity (WHSV) was ca. $0.2 \mathrm{~h}^{-1}$. Product analysis was performed by on-line gas chromatography (PerkinElmer Autosystem) using a Carboxen 1000 column (45/60 mesh, packing density $0.5 \mathrm{~g} / \mathrm{ft}$, length $2 \mathrm{ft}$, ID $2.1 \mathrm{~mm}$, Supelco) and a flame ionization detector.

\section{Results and Discussion}

Fig. 1a shows the X-ray diffractograms of silicasupported samples. The diffraction lines corresponding to crystalline $\mathrm{Zr}\left(\mathrm{SO}_{4}\right)_{2} \cdot 4 \mathrm{H}_{2} \mathrm{O}$, PDF [8-495], are present in the diffractograms of the impregnated silica samples even at loadings as low as $10 \mathrm{wt} \%$. No other reflections were detected in these diffractograms. During calcination the $\mathrm{Zr}\left(\mathrm{SO}_{4}\right)_{2} \cdot 4 \mathrm{H}_{2} \mathrm{O}$ loses water and can decompose to be transformed into sulfated zirconium oxide [75]. Accordingly, diffraction peaks of tetragonal $\mathrm{ZrO}_{2}$, PDF [42-1164], are observed, and they are present at all concentrations. The peaks are quite broad (FWHM of the (111) peak is ca $1.4^{\circ}$ ), with low intensities, indicating that these $\mathrm{ZrO}_{2}$ crystallites are small. Using Scherrer's formula, $\mathrm{D}=0.9 \lambda / \beta \cos \theta[76]$, where $\beta$ is the FWHM in radians and $\theta$ is the Bragg angle, the mean crystalline domain size of the crystallites detected using XRD is estimated to be $6 \mathrm{~nm}$. Small amounts of monoclinic zirconia may be present in some of these samples, as indicated by a weak reflection at ca. $28.5^{\circ}$ and a shoulder at about $31.5^{\circ}$ on the (101)-reflection of tetragonal zirconia. The composition of the $50 \mathrm{wt} \% \mathrm{ZrO}_{2} / \mathrm{SiO}_{2}$ samples is somewhat surprising in that only minute amounts of crystalline tetragonal and monoclinic zirconia were detected. The diffractogram is dominated by the reflections of the alpha-phase of $\mathrm{Zr}\left(\mathrm{SO}_{4}\right)_{2}$, PDF [24-1492]. Some very weak reflections indicate traces of the beta-phase of $\mathrm{Zr}\left(\mathrm{SO}_{4}\right)_{2}$, PDF [20-1474].

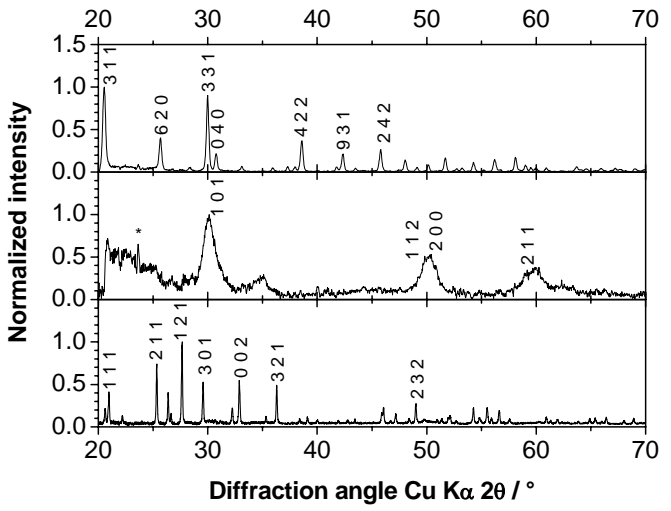

Figure 1a: X-ray diffractograms of silica-supported samples. Top: uncalcined $10 \mathrm{wt} \% \mathrm{ZrO}_{2}$ on $\mathrm{SiO}_{2}$ with Miller indices for $\mathrm{Zr}\left(\mathrm{SO}_{4}\right)_{2} \bullet 4 \mathrm{H}_{2} \mathrm{O}$; middle: calcined $10 \mathrm{wt} \% \mathrm{ZrO}_{2}$ on $\mathrm{SiO}_{2}$ with Miller indices for tetragonal zirconia; bottom: $50 \mathrm{wt} \% \mathrm{ZrO}_{2}$ on silica with Miller indices for $\mathrm{Zr}\left(\mathrm{SO}_{4}\right)_{2}$ alpha phase.
For the alumina support, impregnation and decomposition of the zirconium salt proceed in a different manner as shown in Fig. 1b. The reflections of the support add to the complexity of the diffractograms, and these peaks are broad and ill defined, making an unambiguous assignment difficult. There is a match with the reflections of $\gamma-\mathrm{Al}_{2} \mathrm{O}_{3}$ [PDF 10-425 and 29$63]$ but the presence of $\delta$ - and $\delta^{*}-\mathrm{Al}_{2} \mathrm{O}_{3}$ [PDF 4-877, 461131, and 46-1215] cannot be excluded. The reflections of the zirconium sulfate are not obvious in the uncalcined samples, suggesting stronger interaction between the zirconium and sulfate ions and the alumina support than between those ions and the silica support. This interaction leads to the formation of $\mathrm{Al}_{2}\left(\mathrm{SO}_{4}\right)_{3}$ in the calcination step as indicated by two intense reflections at about $21.3^{\circ}(104)$ and $25.3^{\circ}(113)$ [PDF 30-43] in the diffractograms of all calcined aluminabased samples. Reflections of

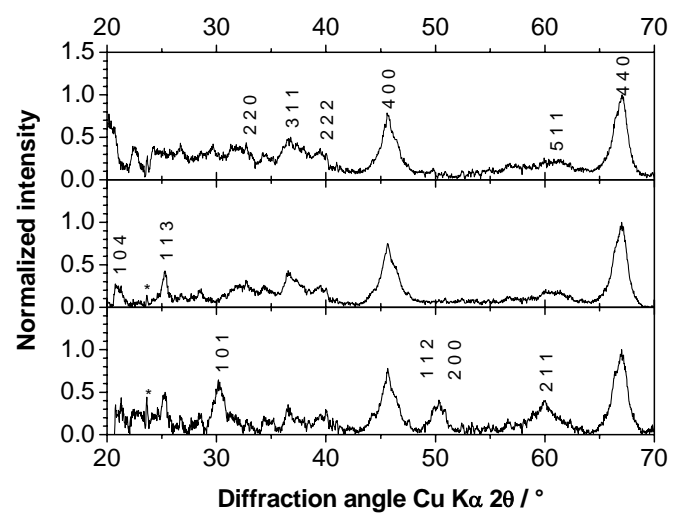

Figure 1b: X-ray diffractograms of alumina-supported samples. Top: uncalcined $10 \mathrm{wt} \% \mathrm{ZrO}_{2}$ on $\gamma-\mathrm{Al}_{2} \mathrm{O}_{3}$ with Miller indices for $\gamma-\mathrm{Al}_{2} \mathrm{O}_{3}$; middle: calcined $20 \mathrm{wt} \% \mathrm{ZrO}_{2}$ on $\gamma$ $\mathrm{Al}_{2} \mathrm{O}_{3}$ with Miller indices for $\mathrm{Al}_{2}\left(\mathrm{SO}_{4}\right)_{3}$; bottom: calcined 50 $\mathrm{wt} \% \mathrm{ZrO}_{2}$ on $\gamma-\mathrm{Al}_{2} \mathrm{O}_{3}$ with Miller indices for tetragonal $\mathrm{ZrO}_{2}$.

Asterisks mark an artifact from the detector; only indices of major reflections are given.

monoclinic zirconia can not entirely be excluded for the 20 and $50 \mathrm{wt} \%$ sample, because contributions from the $\mathrm{Al}_{2} \mathrm{O}_{3}$ interfere. Reflections of tetragonal zirconia are only detected in the diffractogram of the $50 \mathrm{wt} \% \mathrm{ZrO}_{2} / \mathrm{Al}_{2} \mathrm{O}_{3}$ sample. At this content, Guevara-Franco et al. [43] found tetragonal and monoclinic zirconia; Lei et al. [41] observed tetragonal zirconia already at $15 \mathrm{wt} \% \mathrm{ZrO}_{2}$. For our samples, the dispersion of the precursor and of the zirconia on alumina is higher than on silica, and at low zirconium concentrations, particles or thin layers with dimensions below those detectable using $\mathrm{XRD}$ are formed. A stronger interaction of zirconia with alumina than with silica was also postulated by Lei et al. [42]. However, the dispersion of zirconia on silica is strongly preparation-dependent. Zirconia can be dispersed on or interspersed with silica by sol-gel methods using binary solutions $[47,54]$ or it can be dispersed on the extremely large surface area of MCM-41 $[50,67,69]$ by liquid deposition. It may be well dispersed on silica when an alkoxide is used as precursor [30,32] but poorly dispersed 
when nitrate is used [30]. For both supports, silica and alumina, the dispersion may even be dependent on the solvent used during deposition [26]. No general conclusions on the interaction between zirconia and the supports can thus be drawn from one specific preparation route.

TG/DTA of the as-impregnated samples with $10 \mathrm{wt} \%$ $\mathrm{ZrO}_{2}$ (Fig. 2) also demonstrates the different manner of interaction of the two supports with zirconium and sulfate species. On the silica support the decomposition of $\mathrm{Zr}\left(\mathrm{SO}_{4}\right)_{2}$ is completed in the temperature range from 823 to $973 \mathrm{~K}$; the process was followed by an exothermic event in the DTA curve, which, although not of the typical sharpness, may indicate crystallization of $\mathrm{ZrO}_{2}$. On the alumina support, the decomposition occurs over a greater temperature range of from 823 to $1173 \mathrm{~K}$, and there is no significant exothermic effect observed. These experimental findings indicate that the interactions between zirconium and sulfate ions and alumina are stronger than those between zirconium and sulfate ions and silica.
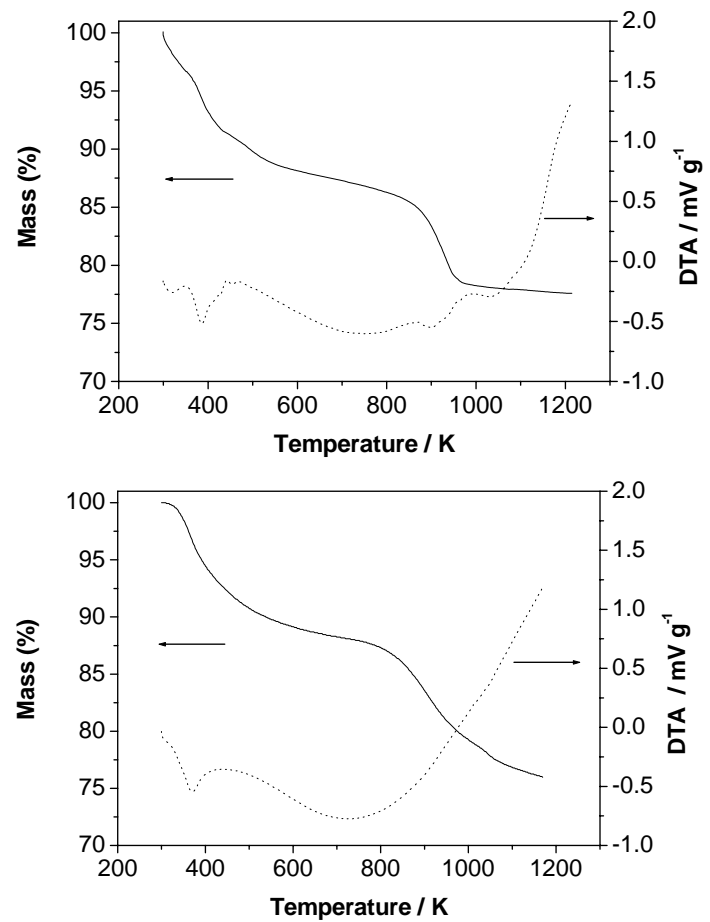

Figure 2: TG/DTA curves of (a) silica and (b) alumina samples as-impregnated with $\mathrm{Zr}\left(\mathrm{SO}_{4}\right)_{2} \bullet 4 \mathrm{H}_{2} \mathrm{O}$ solution, the loadings correspond to $10 \mathrm{wt} \% \mathrm{ZrO}_{2}$.

More differences between the silica- and aluminasupported samples can be seen with electron microscopy. SEM pictures of calcined samples with $20 \mathrm{wt} \% \mathrm{ZrO}_{2}$ on $\mathrm{SiO}_{2}$ and $\gamma-\mathrm{Al}_{2} \mathrm{O}_{3}$ are shown in Fig. 3 and give an overview of the morphology of the samples. The silica particles appear more rounded while the alumina particles are rather edgy. SEM-EDX was used to investigate the homogeneity of the samples before and after calcination. The results are presented in Table 1; as oxygen content from SEM-EDX tends not to be very reliable, oxygen was excluded in the calculations. The silica-supported samples are more heterogeneous as can be seen from the consistently larger standard deviations. Also, it is obvious that about $60 \%$ of the original sulfur are retained in the alumina-supported samples while only about $30 \%$ are retained in the silica-supported samples. A relatively large amount of sulfate thus appears to be bound as $\mathrm{Al}_{2}\left(\mathrm{SO}_{4}\right)_{3}$ or on the surface of alumina in the respective samples. This result is consistent with reports by Grau et al. [46] who found a higher sulfate content in alumina- than in silica-supported sulfated zirconia samples.

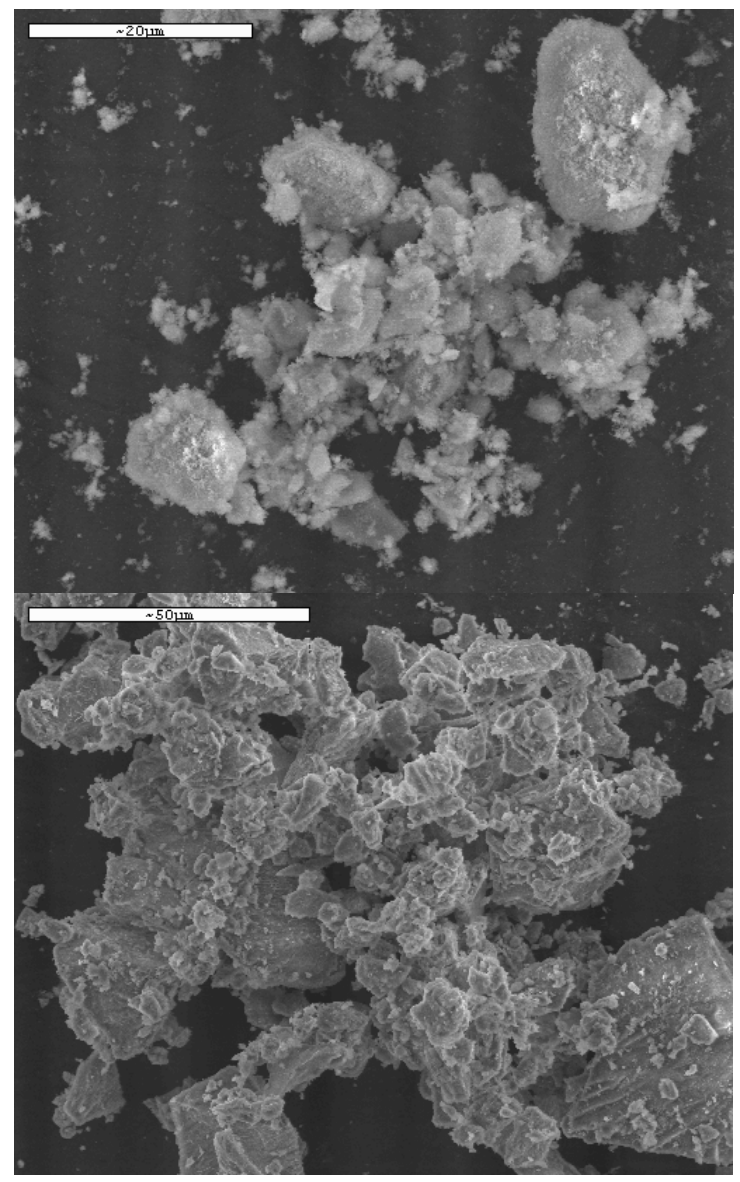

Figure 3: SEM images of calcined samples: (a) $20 \mathrm{wt} \%$ $\mathrm{ZrO}_{2}$ on $\mathrm{SiO}_{2}$; and (b) $20 \mathrm{wt} \% \mathrm{ZrO}_{2}$ on $\gamma-\mathrm{Al}_{2} \mathrm{O}_{3}$.

In the TEM images $\left(20 \mathrm{wt} \% \mathrm{ZrO}_{2}\right)$ of the silicasupported sample (Figs. 4a-4c), zirconia crystallites with sizes up to 5-10 nm can be seen. They are found accumulated (Fig. 4a,b) or as individual particles attached to the $\mathrm{SiO}_{2}$ surface (Fig. 4c). Not all crystallites could be unambiguously assigned to a phase but Fig. 4b shows two crystallites viewed along zone axes. One of them is clearly monoclinic oriented along the [0-11] zone axis revealing lattice fringes separated by $0.31 \mathrm{~nm}, 0.28 \mathrm{~nm}, 0.26 \mathrm{~nm}$ corresponding to the (-111), (111), and (200) planes, respectively. The other crystal reveals lattice fringes separated by $0.30 \mathrm{~nm}$ corresponding to tetragonal $\mathrm{ZrO}_{2}$ oriented along [100] or cubic $\mathrm{ZrO}_{2}$ oriented along [101]. These observations are consistent with the XRD data. In the image shown of the alumina-supported sample (Fig. 4d), zirconia crystals do not stand out from alumina crystallites. Observable lattice spacings can either be assigned to monoclinic $\mathrm{ZrO}_{2}$ or $\gamma$ $\mathrm{Al}_{2} \mathrm{O}_{3}$. The fact that fewer well-defined zirconia crystals and accumulations thereof are present in the images is consistent 
Table 1: Composition according to SEM-EDX

\begin{tabular}{llll}
\hline $\begin{array}{l}\text { Atom \%; } \\
\text { standard deviation }\end{array}$ & $\mathrm{Si}$ or $\mathrm{Al}$ & $\mathrm{Zr}$ & $\mathrm{S}$ \\
\hline $20 \mathrm{wt} \% \mathrm{ZrO}_{2} / \mathrm{SiO}_{2}$ uncalc. & $70.5 \pm 11.5$ & $9.0 \pm 3.8$ & $20.6 \pm 7.7$ \\
$20 \mathrm{wt} \% \mathrm{ZrO}_{2} / \mathrm{Al}_{2} \mathrm{O}_{3}$ uncalc. & $66.8 \pm 4.1$ & $8.6 \pm 0.7$ & $24.7 \pm 3.6$ \\
$20 \mathrm{wt} \% \mathrm{ZrO}_{2} / \mathrm{SiO}_{2}$ calc. & $84.5 \pm 6.3$ & $9.1 \pm 3.6$ & $6.4 \pm 2.8$ \\
$20 \mathrm{wt} \% \mathrm{ZrO}_{2} / \mathrm{Al}_{2} \mathrm{O}_{3}$ calc. & $75.3 \pm 4.2$ & $9.7 \pm 1.0$ & $15.0 \pm 3.6$ \\
\hline
\end{tabular}
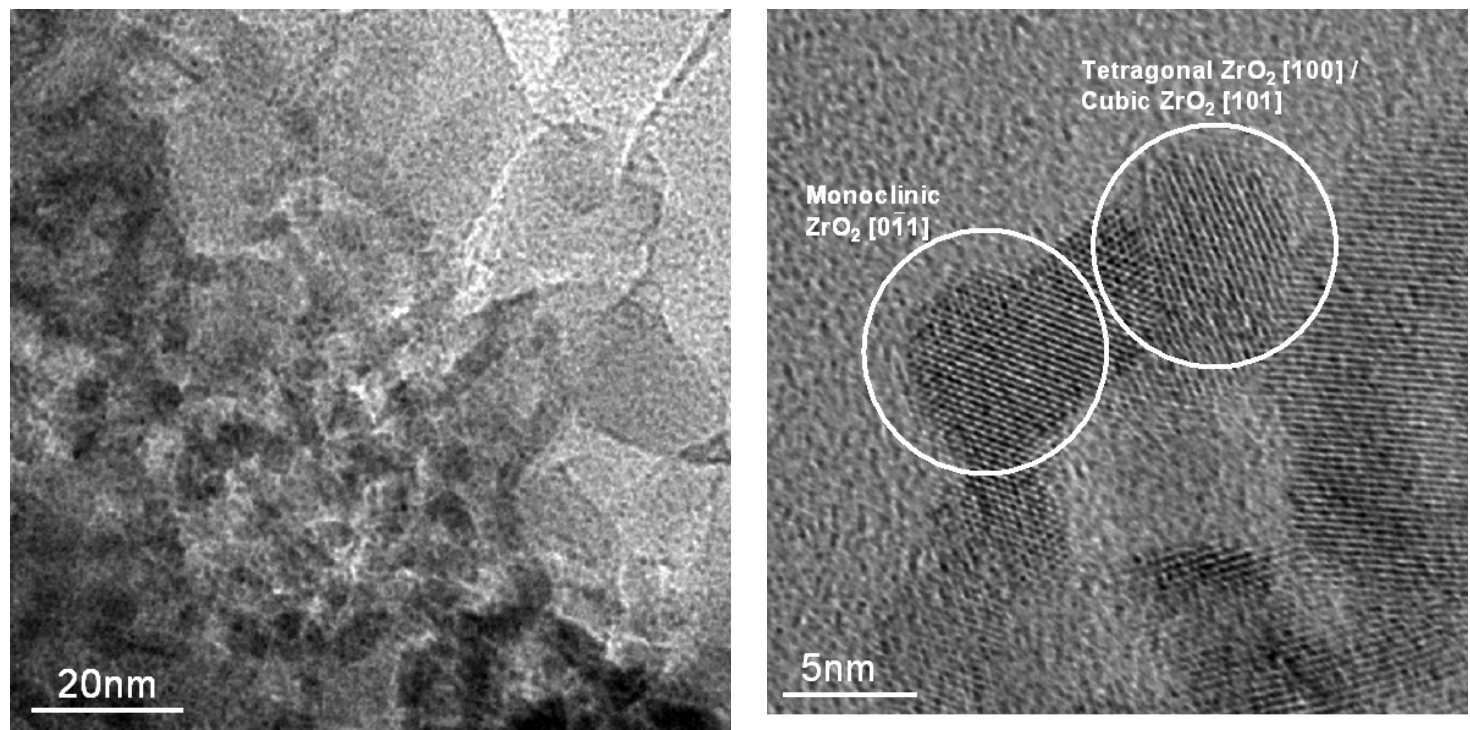

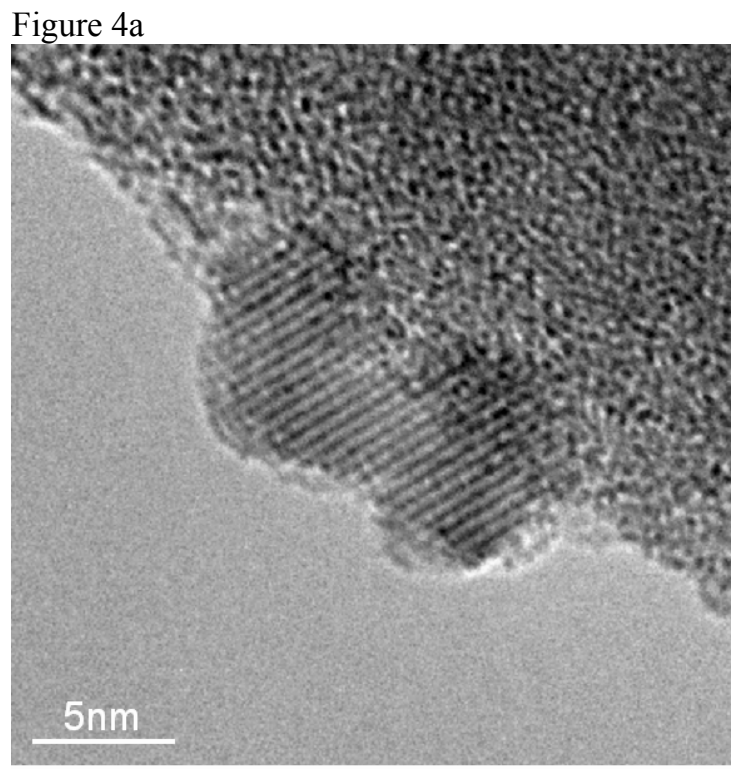

Figure 4c

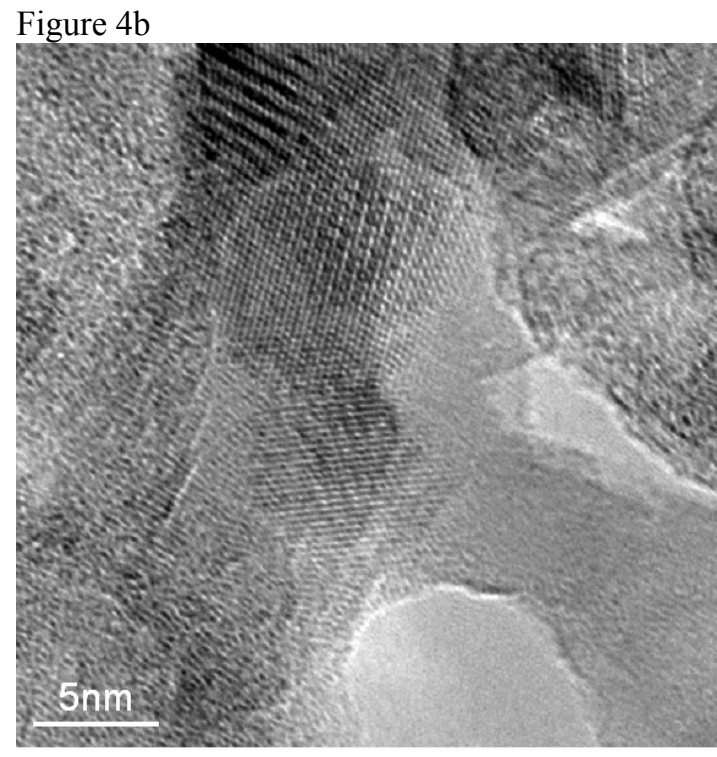

Figure 4d

Figure 4: TEM images of calcined samples: (a)-(c) $20 \mathrm{wt} \% \mathrm{ZrO}_{2}$ on $\mathrm{SiO}_{2}$; and (d) $20 \mathrm{wt} \% \mathrm{ZrO}_{2}$ on $\gamma-\mathrm{Al}_{2} \mathrm{O}_{3}$.

with higher dispersion of zirconia on alumina as indicated by the X-ray diffractograms.

According to the TG/DSC data of the calcined 20 wt $\% \mathrm{ZrO}_{2}$ samples, presented in Figs. 5a and 5b, a higher water content appears to go along with the higher sulfate content. The initial weight loss at low temperatures, which is ascribed to desorption of water from the surface, is about twice as large for the alumina as for the silica-supported $\mathrm{ZrO}_{2}$. Sulfate decomposition occurs at temperatures greater than $923 \mathrm{~K}$ and the corresponding weight loss, which can be taken as a measure of the $\mathrm{SO}_{3}$-content, amounts to $1.5 \%$ for the silica-based samples and to $9 \%$ for the aluminabased sample. These data are consistent with the bonding of sulfate not only to zirconia but also to alumina and the 
presence of $\mathrm{Al}_{2}\left(\mathrm{SO}_{4}\right)_{3}$ as detected by XRD. The sulfur contents do not quite correspond to the SEM-EDX results; potential reasons are (i) only the decomposable sulfate is observed in the thermal analysis, and (ii) errors in absolute values obtained from SEM-EDX, particularly for the interfering $\mathrm{Zr}$ and $\mathrm{S}$ signals.
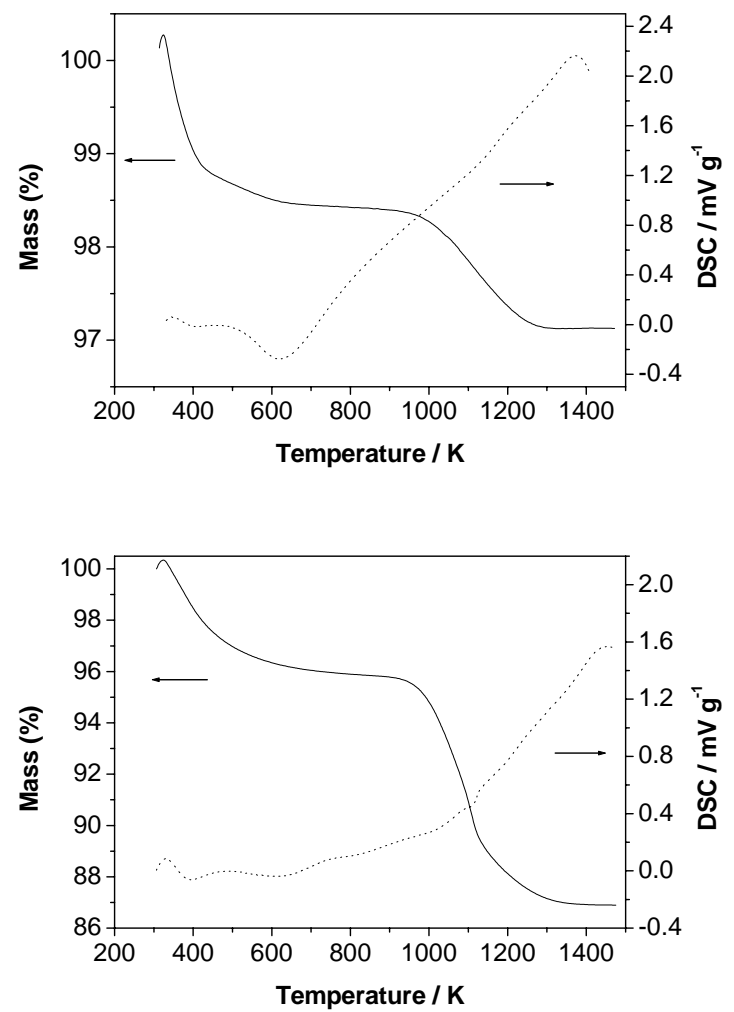

Figure 5: TG/DSC curves of calcined samples: (a) $20 \mathrm{wt} \%$ $\mathrm{ZrO}_{2}$ on $\mathrm{SiO}_{2}$; (b) $20 \mathrm{wt} \% \mathrm{ZrO}_{2}$ on $\gamma-\mathrm{Al}_{2} \mathrm{O}_{3}$.

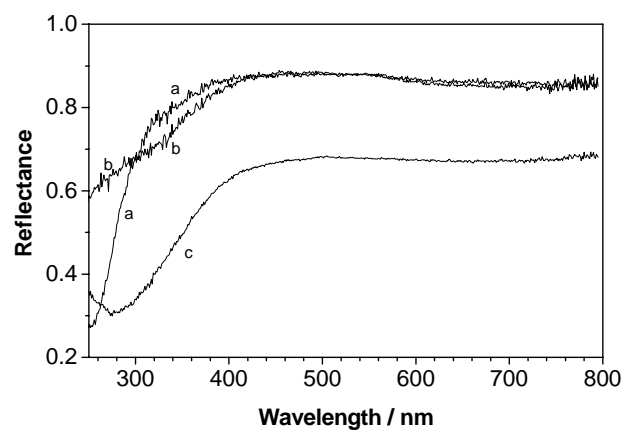

Figure 6: Diffuse reflectance UV-vis spectra of supported and calcined samples (a) the reference sulfated zirconia catalyst MEL Cat. XZO 682/01; (b) $20 \mathrm{wt} \% \mathrm{ZrO}_{2}$ on $\mathrm{SiO}_{2}$; and (c) $20 \mathrm{wt} \% \mathrm{ZrO}_{2}$ on $\gamma-\mathrm{Al}_{2} \mathrm{O}_{3}$.

Fig. 6 shows the diffuse reflectance UV-vis spectra of the calcined samples with $20 \mathrm{wt} \% \mathrm{ZrO}_{2}$ on silica (6b) and on alumina (6c), along with the spectrum of a bulk SZ catalyst, MEL Cat. (6a). Alumina and silica are insulators without defined features in the investigated range; only the reflectivity of the alumina was generally lower. While the reference SZ catalyst absorbs only below $300 \mathrm{~nm}$, both supported catalysts show contributions up to $400-450 \mathrm{~nm}$. The broad absorption cannot be attributed to a shift of the band gap as an effect of zirconia particle size, because these spectra are very similar to the spectra of the uncalcined samples (not shown), which do not contain zirconia. Spectra of finely dispersed zirconia on silica $[25,32]$ do not exhibit contributions at wavelengths higher than 250-300 $\mathrm{nm}$, suggesting that the sulfate in our samples may be part of the species causing the absorption towards longer wavelengths. On the other hand, a broad shoulder extending towards $360 \mathrm{~nm}$ in the spectrum of $\mathrm{ZrO}_{2}$ has been explained by defects and non-stoichiometry [28]. The minimal conclusion from our data is that at least a fraction of the zirconium ions in supported zirconia has a different local environment than zirconium in bulk sulfated zirconia.

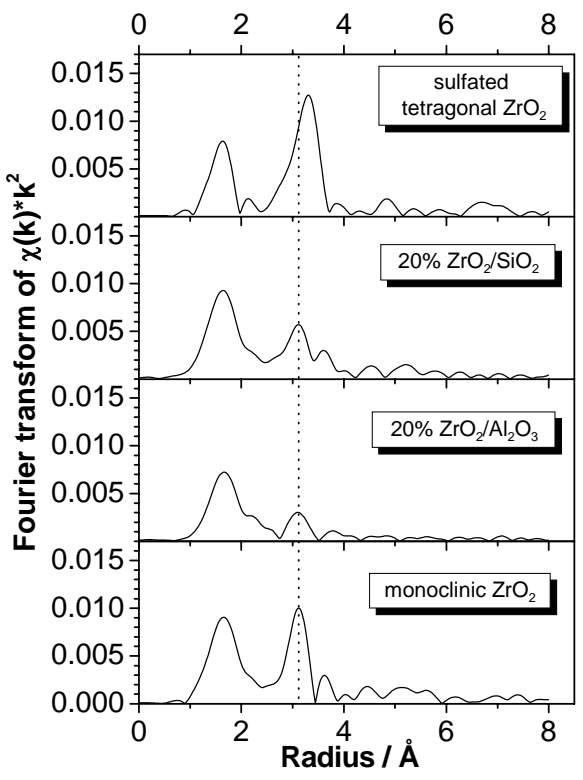

Figure 7: Radial distribution function for the $\mathrm{Zr} \mathrm{K}$ edge of calcined samples, top to bottom: a sulfated tetragonal zirconia; $20 \mathrm{wt} \% \mathrm{ZrO}_{2}$ on $\mathrm{SiO}_{2} ; 20 \mathrm{wt} \% \mathrm{ZrO}_{2}$ on $\gamma-\mathrm{Al}_{2} \mathrm{O}_{3}$; monoclinic zirconia.

The local structures of supported zirconia were characterized with EXAFS. Fig. 7 depicts the pseudo-radial distribution function for the $\mathrm{Zr} \mathrm{K}$ edge of the calcined samples with $20 \mathrm{wt} \% \mathrm{ZrO}_{2}$ and for comparison corresponding data of a tetragonal SZ and a monoclinic $\mathrm{ZrO}_{2}$. The radial distribution function for both supported samples is more similar to that of monoclinic $\mathrm{ZrO}_{2}$ than to that of the tetragonal SZ. The broader $\mathrm{Zr}-\mathrm{O}$ first shell of the monoclinic reference is a combination of seven different $\mathrm{Zr}-\mathrm{O}$ distances while the tetragonal structure has only two different $\mathrm{Zr}$-O distances. The maximum at about 3.1 angstroms is formed by combinations of $\mathrm{Zr}-\mathrm{Zr}$ distances for both references, and is of lower amplitude for the supported samples than for the references, indicating greater disorder, dispersion, or a combination of ordered structures. Additionally such changes may indicate next nearest neighbors that are 
not $\mathrm{Zr}$, for instance $\mathrm{Zr}$-Si which has been reported for silica-supported zirconium oxides [33] or perhaps Zr-Al. The amplitude of the radial distribution for the aluminasupported sample is lower than that of the silica-supported sample and this may indicate more disorder or a broader combination of structures or more highly dispersed zirconium species. The small $\mathrm{ZrO}_{2}$ particles on silica and the highly dispersed $\mathrm{ZrO}_{2}$ on alumina show somewhat similar local coordination around the $\mathrm{Zr}$ ions.

Both catalyst systems with up to $20 \mathrm{wt} \% \mathrm{ZrO}_{2}$ on $\mathrm{SiO}_{2}$ and $\gamma-\mathrm{Al}_{2} \mathrm{O}_{3}$ can be considered as $\mathrm{SZ}$ catalysts with a high fraction of well-dispersed, nanosized sulfated zirconia. It is thus meaningful to compare their catalytic behavior with the MEL Cat., in order to determine the effect of the bulk phase. The isomerization tests were carried out at 378 $\mathrm{K}$ at a WHSV of about $0.2 \mathrm{~h}^{-1}$. The rates of $n$-butane isomerization to isobutane for $\mathrm{ZrO}_{2}$ supported on silica and alumina, for a calcined, unsupported $\mathrm{Zr}\left(\mathrm{SO}_{4}\right)_{2} \bullet 4 \mathrm{H}_{2} \mathrm{O}$, and for the MEL Cat. are depicted in Fig. 8. The most active catalyst is the MEL Cat. material, with a maximal isomerization rate of greater than $25 \mu \mathrm{mol} \mathrm{h}^{-1} \mathrm{~g}_{\mathrm{ZrO}_{2}}{ }^{-1}$ and an isomerization selectivity of $95 \%$ at the maximal conversion. The other catalyst with bulk zirconia phase, calcined $\mathrm{Zr}\left(\mathrm{SO}_{4}\right)_{2} \bullet 4 \mathrm{H}_{2} \mathrm{O}$, is much less active, the maximum isomerization rate is ca. $0.7 \mu \mathrm{mol} \mathrm{h}^{-1} \mathrm{~g}_{\mathrm{ZrO} 2}{ }^{-1}$ under the test conditions, and at this low level of conversion the selectivity for isomerization products is $100 \%$ (Fig. 8a). Both catalysts pass through a period of increasing conversion, reach a maximum after 4 and $0.5 \mathrm{~h}$ on stream, respectively, and then partially deactivate to a "steady state" of activity. The catalyst obtained from the MEL precursor exhibits a remaining activity that is still larger than the maximum activity of the calcined $\mathrm{Zr}\left(\mathrm{SO}_{4}\right)_{2} \bullet 4 \mathrm{H}_{2} \mathrm{O}$ catalyst or any of the other samples.

For the supported catalysts with up to $20 \mathrm{wt} \% \mathrm{ZrO}_{2}$ loading, the short-term high activity is absent (Figs. $8 \mathrm{~b}$ and $8 \mathrm{c})$. The catalysts seem to undergo a long induction period. The activity increases gradually with time on stream for up to the maximum test time of $20 \mathrm{~h}$ and is more stable than those of the unsupported SZ catalysts. A similar observation of steady conversion was reported by Guo et al. [56], who compared the performance of silica-supported SZ and unsupported SZ in alkylation. There is no striking difference between the silica- and the alumina-based materials although the silica-supported materials contain detectable (XRD) amounts of tetragonal zirconia.

The profiles of supported catalysts with $50 \mathrm{wt} \% \mathrm{ZrO}_{2}$ show a maximum catalytic activity at early time on stream and a more or less steady activity between 2 and $15 \mathrm{~h}$ on stream. Samples made from a raw material with a high content of zirconium and sulfate quite logically approach the catalytic performance obtained for the calcined zirconium sulfate.

The isomerization selectivity of all these supported catalysts is $100 \%$ under the test conditions. There are very few data in the literature that are comparable to our zirconia contents and reaction conditions, and that show the time on stream behavior. Lei et al. $[41,42]$ e.g. tested $\mathrm{ZrO}_{2} / \gamma-\mathrm{Al}_{2} \mathrm{O}_{3}$ and $\mathrm{ZrO}_{2} / \mathrm{SiO}_{2}$ catalysts in $n$-butane isomerization at $523 \mathrm{~K}$, but under their conditions, the catalysts deactivated from the beginning.
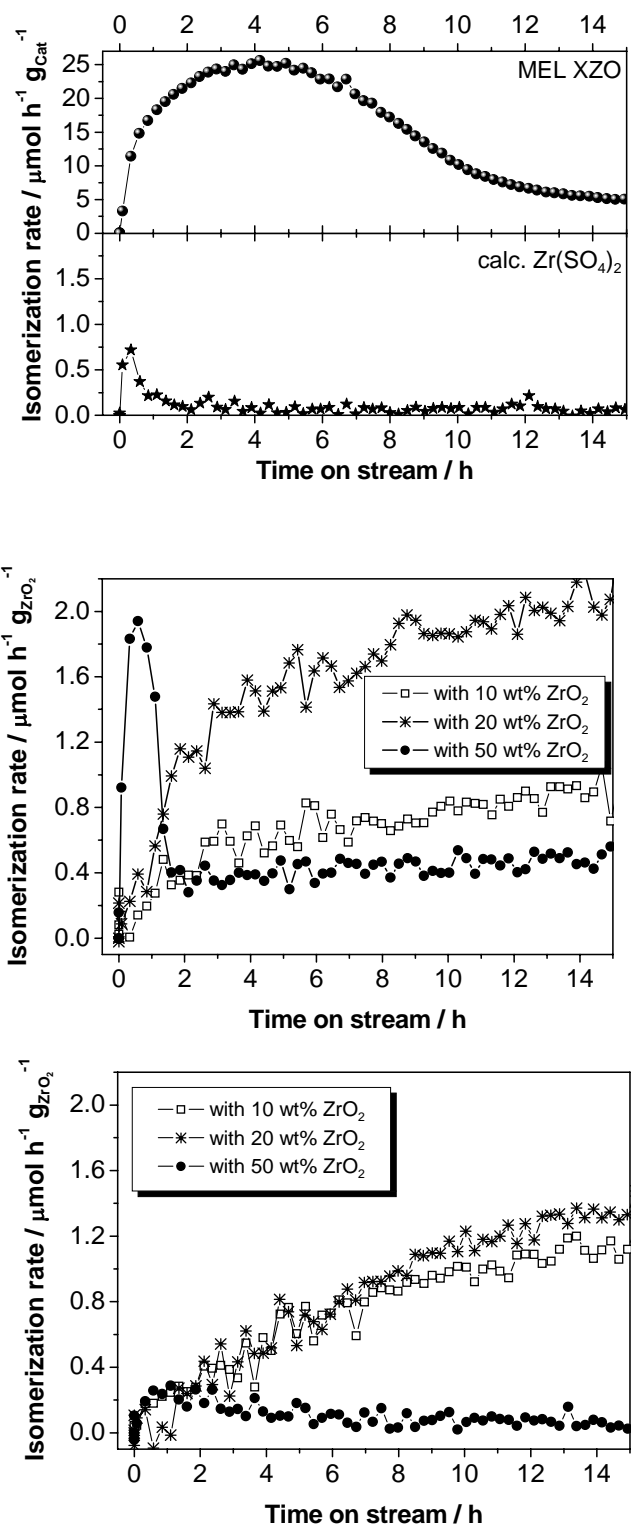

Figure 8: Catalytic test results at $378 \mathrm{~K}$ with $30 \mathrm{ml} / \mathrm{min} 1$ vol\% $n$-butane in $\mathrm{N}_{2}$ over catalysts containing $200.0 \mathrm{mg}$ $\mathrm{ZrO}_{2}$ : (a) $\mathrm{MEL}$ Cat. $\mathrm{XZO} 682 / 01$, top and calcined $\mathrm{Zr}\left(\mathrm{SO}_{4}\right)_{2} \bullet 4 \mathrm{H}_{2} \mathrm{O}$, bottom; (b) silica-supported samples; and (c) alumina-supported samples.

Although the maximum $n$-butane isomerization rates achieved with the supported samples were 1-2 orders of magnitude lower than that of the calcined commercial material, all samples were active, no matter whether they contained detectable amounts of bulk tetragonal zirconia or not. It follows that there must be a species responsible for the basic activity, and these sites are rather easily formed as long as zirconium and sulfate are present in the raw material and the calcination temperature is within a certain range. When these conditions are fulfilled, it is almost impossible to make a totally inactive material. Consistent with 
this is the observation that the tetragonal phase is not a prerequisite for catalytic activity; e.g. monoclinic zirconia has been reported as active [8].

On the basis of the XRD data and the hypothesis that the tetragonal phase should be particularly active, three samples are expected to perform outstandingly: 10 and 20 $\mathrm{wt} \% \mathrm{ZrO}_{2} / \mathrm{SiO}_{2}$ and $50 \mathrm{wt} \% \mathrm{ZrO}_{2} / \mathrm{Al}_{2} \mathrm{O}_{3}$. This is obviously not the case. In the silica series, the highest maximum activity is, though short-lived, displayed by the $50 \% \mathrm{ZrO}_{2}$ sample, which contains zirconium sulfate and hardly any tetragonal zirconia. The $50 \mathrm{wt} \% \mathrm{ZrO}_{2} / \mathrm{Al}_{2} \mathrm{O}_{3}$ sample, which is the only one in the series containing detectable (XRD) amounts of tetragonal zirconia, is overall less active than the other two alumina-supported samples, which do not contain tetragonal zirconia. The results of the aluminaseries may be somewhat obscured by the fact that sulfate is associated with zirconia and alumina. Nevertheless, a simple correlation between the observation of high catalytic activity and the presence of the tetragonal zirconia phase can not be made.

Rather than the presence or absence of tetragonal zirconia, the site density may be a decisive parameter, because a low site density may allow only for the slower monomolecular isomerization mechanism while a high density might favor the faster (lower activation energy [77]) bimolecular mechanism. Dilution of active sites, equal to the presence of an inert material such as a support, appears advantageous in that it prevents rapid deactivation that goes along with the bimolecular mechanism [2]. Consistent with this hypothesis, only the supported materials with high zirconia content deactivate during the observation span. The origin of the pronounced high initial activity in the case of the $50 \mathrm{wt} \% \mathrm{ZrO}_{2} / \mathrm{SiO}_{2}$ sample may be the zirconium sulfate phase, which possibly provides a high site density. As an active phase in unsupported sulfated zirconia catalysts, a surface sulfate can be imagined, because S K edge absorption spectra of such materials resemble the spectrum of zirconium sulfate [15].

Our investigations show that the correlation between (high) activity and phase composition is much more complex than previously thought [18]. Catalysts that do not contain tetragonal zirconia may exhibit considerable activity while catalysts that do contain tetragonal zirconia may perform moderately. Reaction profiles here and in the literature show a rapid, though never complete, deactivation. This behavior can be explained by two models: (i) two types of sites are present, a highly active but deactivating type, and a less active but stable type or (ii) site ensembles

\section{References}

[1] M. Hino, S. Kobayashi and K. Arata, J. Am. Chem. Soc. 101 (1979) 6439.

[2] R. Ahmad, J. Melsheimer, F.C. Jentoft and R. Schlögl, J. Catal. 218 (2003) 365.

[3] J.C. Yori, M.A. D'Amato, G. Costa and J.M. Parera, J. Catal. 153 (1995) 218.

[4] H. Liu, V. Adeeva, G.D. Lei and W.M.H. Sachtler, J. Molec. Catal. A: Chemical 100 (1995) 35. and isolated sites are present, and only ensembles deactivate because they evoke the bimolecular mechanism with its side products, which eventually transform into coke [2].

\section{Summary and Conclusions}

The interaction between zirconium ions and silica is weak, small particles of tetragonal zirconia form on the silica support after impregnation with zirconium sulfate solutions and calcination, also at low zirconia loadings (10 and $20 \mathrm{wt} \%$ ). On alumina with the same loadings, the dispersion of zirconia is higher than on silica, formation of a crystalline zirconia phase is not observable. Additionally, sulfate reacts with the support to form $\mathrm{Al}_{2}\left(\mathrm{SO}_{4}\right)_{3}$, which increases the sulfate content in these samples. UV-vis and XAFS spectra show for both supports that at a content of $20 \mathrm{wt} \%$ the local zirconium environment in supported zirconia is decidedly different from that in bulk tetragonal zirconia.

All supported sulfated zirconia materials were active. With increasing zirconium sulfate content in the precursor, the reaction profiles resembled more and more that of the catalyst made by calcination of $\mathrm{Zr}\left(\mathrm{SO}_{4}\right)_{2} \bullet 4 \mathrm{H}_{2} \mathrm{O}$, i.e. the conversion reached a maximum within the first 2 hours on stream and then decreased. For the investigated series of samples, neither the maximum activity nor the steady state activity correlate with the presence of detectable (XRD) amounts of tetragonal zirconia, suggesting that other factors such as site density or zirconia defect structure are more important.

\section{Acknowledgment}

B. Bems, A. Dassenoy, E. Kitzelmann, V.V. Roddatis, G. Tzolova-Müller, and G. Weinberg are thanked for their help in characterizing the samples, F. Girgsdies for discussion of the XRD data, J.B. Wagner for analysis of the TEM images, T. Ressler for arranging beamtime at Hasylab, and R. Schlögl for long-lasting support.
[5] S.Y. Kim, J.G. Goodwin Jr. and D. Galloway, Catal. Today 63 (2000) 21.

[6] X. Song and A. Sayari, Catal. Rev. Sci. Eng. 38 (1996) 329.

[7] G.D. Yadav and J.J. Nair, Microporous Mesoporous Mat. 33 (1999) 1.

[8] W. Stichert and F. Schüth, J. Catal. 174 (1998) 242.

[9] C. Morterra, G. Cerrato, G. Meligrana, M. Signoretto, F. Pinna and G. Strukul, Catal. Lett. 73 (2001) 113.

[10] K. Arata, Adv. Catal. 37 (1990) 165. 
[11] J.B. Laizet, A.K. Søiland, J. Leglise and J.C. Duchet, Topics in Catalysis 10 (2000) 89.

[12] C.Y. Hsu, C.R. Heimbuch, C.T. Armes and B.C. Gates, J. Chem. Soc., Chem. Commun. (1992) 1645.

[13] F.C. Lange, T.-K. Cheung and B.C. Gates, Catal. Lett. 41 (1996) 95.

[14] A. Hahn, T. Ressler, R.E. Jentoft and F.C. Jentoft, J. Chem. Soc., Chem. Commun. (2001) 537.

[15] R.E. Jentoft, A. Hahn, F.C. Jentoft and T. Ressler. J. Synchrotron Rad. 8 (2001) 563.

[16] F.C. Jentoft, A. Hahn, J. Kröhnert, G. Lorenz, R.E. Jentoft, T. Ressler, U. Wild and R. Schlögl, J. Catal. 224 (2004) 124.

[17] B.S. Klose, R.E. Jentoft, A. Hahn, T. Ressler, J. Kröhnert, S. Wrabetz, X. Yang and F.C. Jentoft, J. Catal. 217 (2003) 487.

[18] X. Yang, F.C. Jentoft, R.E. Jentoft, F. Girgsdies and T. Ressler, Catal. Lett. 81 (2002) 25.

[19] J. Klein and W.F. Maier, Chem. Mater. 11 (1999) 2584.

[20] J.M. Dominguez, J.L. Hernandez and G. Sandoval, Appl. Catal. A: General 197 (2000) 119.

[21] H.J.M. Bosman, E.C. Kruissink, J. van der Spoel and F. van den Brink, J. Catal. 148 (1994) 660.

[22] H.J.M. Bosman, A.P. Pijpers and A.W.M. Jaspers, J. Catal. 161 (1996) 551

[23] A.A.S. Alfaya, Y. Gushikem and S.C. de Castro, Microporous Mesoporous Mat. 39 (2000) 57.

[24] J.B. Miller and E.I. Ko, Catal. Today 35 (1997) 269.

[25] S.-C. Moon, M. Fujino, H. Yamashita and M. Anpo, J. Phys. Chem. B 101 (1997) 369.

[26] C. Marquez-Alvarez, J.L.G. Fierro, A. Guerrero-Ruiz and I. Rodriguez-Ramos, J. Colloid Interface Sci. 159 (1993) 454.

[27] S. Damyanova, P. Grange and B. Delmon, J. Catal. 168 (1997) 421.

[28] A.C. Faro Jr., K.R. Souza, V.L.D.L. Camorim and M.B. Cardoso, Phys. Chem. Chem. Phys. 5 (2003) 1932.

[29] S. Naito and M. Tanimoto, J. Catal. 154 (1995) 306.

[30] A.C.Q.M. Meijers, A.M. de Jong, L.M.P. van Gruijthuijsen and J.W. Niemantsverdriet, Appl. Catal. 70 (1991) 53.

[31] S. Naito and M. Tanimoto, J. Catal. 154 (1995) 306.

[32] X. Gao, J.L.G. Fierro and I.E. Wachs, Langmuir 15 (1999) 3169.

[33] K. Okumura and Y. Iwasawa, J. Catal. 164 (1996) 440.

[34] A. Tuel, S. Gontier and R. Teissier, Chem. Commun. (1996) 651.

[35] D.J. Jones, J. Jiménez-Jiménez, A. Jiménez-López, P. Maireles-Torres, P. Olivera-Pastor, E. Rodriguez-Castellón and J. Rozière, Chem. Commun. (1997) 431.

[36] K. Chaudhari, R. Bal, T. Kr. Das, A. Chandwadkar, D. Srinivas and S. Sivasanker, J. Phys. Chem. B 104 (2000) 11066.

[37] X.X. Wang, F. Lefebvre, J. Patarin and J.-M. Basset, Microporous Mesoporous Mat. 42 (2001) 269.

[38] B.L. Newalkar, J. Olanrewaju and S. Komarneni, J. Phys. Chem. B 105 (2001) 8356.

[39] W. Hua and J. Sommer, Appl. Catal. A: General 227 (2002) 279.

[40] T. Lei, J.S. Xu, W.M. Hua and Z. Gao, Appl. Catal. A: General 192 (2000) 181.

[41] T. Lei, J.S. Xu, W.M. Hua, Y. Tang and Z. Gao, Catal. Lett. 61 (1999) 213.

[42] T. Lei, J.S. Xu, Y. Tang, W.M. Hua and Z. Gao, Appl. Catal. A: General 192 (2000) 181.

[43] M.L. Guevera-Franco, S. Robles-Andrade, R. GarcíaAlamilla, G. Sandoval-Robles and J.M. Domínguez-Esquivel, Catal. Today 65 (2001) 137.

[44] L. Ben Hamouda, A. Ghorbel and F. Figueras, J. Sol-Gel Sci. Techn. 26 (2003) 831.
[45] P. Iengo, M. Di Serio, V. Solinas, D. Gazzoli, G. Salvio and E. Santacesaria, Appl. Catal. A: General 170 (1998) 225.

[46] J.M. Grau, C.R. Vera and J.M. Parera, Appl. Catal. A: General 172 (1998) 311.

[47] D.J. Rosenberg, F. Coloma and J.A. Anderson, J. Catal. 210 (2002) 218.

[48] C.-L. Chen, T. Li, S. Cheng, H.-P. Lin, C.J. Bhongale and C.Y. Mou, Microporous Mesoporous Mat. 50 (2001) 201.

[49] J.B. Miller and E.I. Ko, Chem. Engr. J. 64 (1996) 273.

[50] Q.-H. Xia, K. Hidajat and S. Kawi, Chem. Commun. (2000) 2229.

[51] P. Iengo, M. Di Serio, A. Sorrentino, V. Solinas and E. Santacesaria, Appl. Catal. A: General 167 (1998) 85.

[52] R. Barthos, F. Lónyi, J. Engelhardt and J. Valyon, Topics in Catalysis 10 (2000) 79.

[53] D.J. Rosenberg, B. Bachiller-Baeza, T.J. Dines and J.A. Anderson, J. Phys. Chem. B. 107 (2003) 6526.

[54] J.A. Navio, G. Colón, M. Macías, J.M Campelo, A.A. Romero and J.M. Marinas, J. Catal. 161 (1996) 605.

[55] T. Lopez, J. Navarrete, R. Gomez, O. Novaro, F. Figueras and H. Armendariz, Appl. Catal. A: General 125 (1995) 217.

[56] C. Guo, Z. Yu, Z. Qian, J. Huang and Y. Xu, Proceedings of the International Symposium on Acid-Base Catalysis II, Sapporo, December 2-4, 1993, Eds. B. Delmon, J.T. Yates, Stud. Surf. Sci. Catal. 90 (1994) 543.

[57] J.A. Navio, G. Colón, M. Macias, J.M. Campelo, A.A. Romero and J.M. Marinas, J. Molec. Catal. A: Chemical 135 (1998) 155.

[58] Q.-H. Xia, K. Hidajat and S. Kawi, J. Catal. 205 (2002) 318.

[59] Y. Sun, L. Zhu, H. Lu, R. Wang, S. Lin, D. Jiang and F.-S. Xiao, Appl. Catal. A: General 237 (2002) 21.

[60] C.-L. Chen, T. Li, S. Cheng, N. Xu and C.-Y. Mou, Catal. Lett. 78 (2002) 223.

[61] C.-L. Chen, S. Cheng, H.-P. Lin, S.-T. Wong and C.-Y. Mou, Appl. Catal. A: General 215 (2001) 21.

[62] W. Wang, C.-L. Chen, N.P. Xu, S. Han, T. Li, S. Cheng and C.-Y. Mou, Catal. Lett. 83 (2002) 281.

[63] P. Canton, R. Olindo, F. Pinna, G. Strukul, P. Riello, M. Meneghetti, G. Cerrato, C. Morterra and A. Benedetti, Chem. Mater. 13 (2001) 1634.

[64] W. Hua, Y. Xia, Y. Yue and Z. Gao, J. Catal. 196 (2000) 104.

[65] C. Miao, W. Hua, J. Chen and Z. Gao, Catal. Lett. 37 (1996) 187.

[66] Z. Gao, Y. Xia, W. Hua and C. Miao, Topics in Catalysis 6 (1998) 101.

[67] Y.D. Xia, W.M. Hua, Y. Tang and Z. Gao, Chem. Commun. (1999) 1899.

[68] Y. Xia, W. Hua and Z. Gao, Appl. Catal. A: General 185 (1999) 293.

[69] M. Perez-Luna, J.A. Toledo-Antonio, F. Hernandez-Beltrán, H. Armendariz and A. Garcia Borquez, Catal. Lett. 83 (2002) 201.

[70] E. Zhao, Yu. Isaev, A. Sklyarov and J.J. Fripiat, Catal. Lett. 60 (1999) 173.

[71] R. Olindo, A. Goeppert, D. Habermacher, J. Sommer and F. Pinna, J. Catal. 197 (2001) 344.

[72] Y. Xia, W. Hua and Z. Gao, Catal. Lett. 55 (1998) 101.

[73] T. Ressler, J. Synchrotron Rad. 5 (1998) 118.

[74] T. Ressler, S.L. Brock, J. Wong and S.L. Suib, J. Phys. Chem. B 103 (1999) 6407.

[75] K. Arata, M. Hino and N. Yamagata, Bull. Chem. Soc. Jpn. 63 (1990) 244.

[76] B.D. Cullity, Elements of X-ray Diffraction, $2^{\text {nd }}$ Edition (Addison-Wesley Publishing Company Inc., Boston, 1978).

[77] H. Matsuhashi, H. Shibata, H. Nakamura and K. Arata, Appl. Catal. A: General 187 (1999) 99. 